\title{
Kerosene-Induced Panniculitis in Iraqi Patients
}

\author{
Khalifa E. Sharquie $^{1 *}$, Adil A. Noaimi ${ }^{1}$, Maha S. Younis ${ }^{2}$, Bashar S. Al-Sultani ${ }^{3}$ \\ ${ }^{1}$ Department of Dermatology, College of Medicine, University of Baghdad, Baghdad, Iraq \\ ${ }^{2}$ Department of Psychiatry, College of Medicine, Baghdad University, Baghdad, Iraq \\ ${ }^{3}$ Department of Dermatology, Baghdad Teaching Hospital, Medical City, Baghdad, Iraq \\ Email:"ksharquie@ymail.com, adilnoaimi@yahoo.com, Maha.younis@gmail.com, bashar-sami83@yahoo.com
}

Received 26 September 2014; revised 31 October 2014; accepted 7 November 2014

Copyright (C) 2014 by authors and Scientific Research Publishing Inc.

This work is licensed under the Creative Commons Attribution International License (CC BY).

http://creativecommons.org/licenses/by/4.0/

c) (i) Open Access

\begin{abstract}
Background: Kerosene is a common household stuff that has been used as accidental oral poisoning material in children and as suicidal attempt in adults. In the last decade intradermal kerosene injection has been commonly used to induce dermatitis artefecta as a part of emotional upset. $0 b$ jective: To evaluate the clinical cases of intradermal kerosene injection in Iraqi patients. Patients and Methods: This is a descriptive case study that had been conducted in Department of Dermatology Baghdad Teaching Hospital, Baghdad, Iraq during the period from Jan. 2003 to Dec. 2012. History and full clinical examination were performed including all sociodemographic aspects associated with this condition. Psychiatric evaluation was done for each patient. Results: All eleven patients had single lesion except that two had two lesions. They were distributed on accessible areas on the limbs. The exact diagnosis was not reached for at least few weeks after kerosene injection. The patients denied any kerosene injection, but after a while they all admitted that the cause of their rash, severe emotional tension was observed at the time of kerosene injection as they had sociopsychological disturbances. The initial rash was erythematous indurated tender plaque that was gradually increasing in size simulating the picture of panniculitis and then followed by rupture of lesion and associated pyoderma, forming chronic discharging ulcer. Patients were managed by topical and systemic antibiotics until complete resolution leaving a big ugly scar that was treated by topical steroids to improve its cosmetic appearance. Conclusions: Kerosene intradermal injection is an increasing problem among Iraqi adult females and it should be suspected in any patient with chronic discharging ulcer on accessible areas like limbs.
\end{abstract}

\section{Keywords}

Kerosene, Panniculitis, Emotional Tension

\footnotetext{
${ }^{*}$ Corresponding author.
}

How to cite this paper: Sharquie, K.E., Noaimi, A.A., Younis, M.S. and Al-Sultani, B.S. (2014) Kerosene-Induced Panniculitis in Iraqi Patients. Journal of Cosmetics, Dermatological Sciences and Applications, 4, 323-328. 


\section{Introduction}

Kerosene is one of petrolatum products that are commonly used for heating in houses during winter time. Kerosene poisoning is frequently encountered in Iraqi hospitals as children and toddlers accidently ingest it, probably due to its unlabeled containers. In the last few years we have come across cases of kerosene injection as an attempt for suicide. Kerosene is a hydrocarbon compound that is known to cause toxicity which affects many different organs according to the dose and route of exposure, whether through ingestion, inhalation, intravenous injection or dermal injection. The chemical properties of the individual hydrocarbon determine the specific toxicity, while the dose and route of ingestion affect organs which are exposed to the toxicity. If these hydrocarbons come in contact with the skin surface, they can cause dryness, scaling and sometimes severe dermatitis [1]. Skin absorption of kerosene has been demonstrated to be fairly rapid, but it is limited to approximately $10 \%-15 \%$ after 24 hours of the applied dose [2]. When injected into skin, kerosene causes an intense local inflammatory reaction with necrosis of the skin, fatty tissue and possibly underlying muscle [3] [4]. Chronic exposure can result in renal failure and/or degenerative changes of livers or kidneys. Signs and symptoms of overexposure include giddiness, headache, dizziness, nausea, vomiting, incoordination, narcosis, stupor, coma, unconsciousness, weight loss, anemia, renal failure, and pains in the limbs peripheral numbness, parasthesia, drying and cracking of skin, and rashes or spots on skin.

Intradermal kerosene injection causing fasciitis and necrosis is self mutilation practice that has been reported among adults [5] [6], however only four cases are documented and all of them are in Arab communities.

In Iraq it is not an uncommon problem among children to have accidental oral ingestion or inhalation of kerosene while for adults oral intake or bathing with kerosene is used as a suicidal attempt.

During Iran-Iraqi war 1980-1988 it is a well known practice among soldiers during army attacks to do intradermal injection of kerosene to induce dermatitis in order to have sick leave (Sharquie observations).

In the last ten years and specifically after American occupation of Iraq there is a new trend among young adults to induce self infliction by intradermal kerosene injection under the pressure of their emotional problems.

Although household kerosene is a familiar tool for committing suicide whether an attempt or complete by self burning in Middle East countries [7]. Very few literatures report cases using it for self mutilation [8]. General studies that assess suicidal behavior are rare in the Arab world given the fact that suicide is considered as a disgraceful act prohibited by religion, condemned by society and intrigued by legal consequences [7].

Psychiatric evaluation should be done for the attempters in order to assess the presence of any psychological disorders. In reviewing the clinical picture, time was an important factor [9]. Delay in management would have allowed the noxious agents to cause much irreversible necrosis and possible suppuration. Since the injected material penetrates slowly, immediate and adequate surgical debridement with possible fasciatomy is the best initial treatment, followed by repeated and relentless debridement with dressings [10].

So the aim of the present work is to report cases of intradermal kerosene injection causing panniculitis and fasciitis and to evaluate the different clinical and psychological aspects of this self-induced disease.

\section{Patients and Methods}

This is a descriptive case study that had been carried out in Department of Dermatology and Venereology Baghdad Teaching Hospital, Baghdad, Iraq during the period from Jan. 2003 to Dec. 2012.

Eleven cases - ten females and one male were seen, whose ages range from $17-25$ year with a mean 21.5 years. Full history and examination was carried out to evaluate the sociopsychological aspects and the emotional tension of the patients and to evaluate the course of the disease from the time of the injection. Digital photographs were taken using SONY Cyber-Shot T300 10.1 MP for each patient in good illumination.

Formal consent was taken from each patient after full explanation about the nature and the goal of the present work. Ethical approval was obtained from the Scientific Council of Dermatology and Venereology-Arab Board for Medical Specializations.

\section{Results}

All eleven patients (Table 1) had severe emotional tension as a result of social, economical and psychological problems. All patients denied the self injection of kerosene but when confronted with the injection, they all admitted the cause. Psychiatric assessment revealed absence of psychotic disorders or cognitive impairment 
Table 1. Showing features of cases with kerosene intradermal injection.

\begin{tabular}{|c|c|c|c|c|}
\hline No. & Age & Gender & Site & Type \\
\hline 1 & 23 & M & Both Forearm & Ulcer \& Pyoderma \\
\hline 2 & 19 & $\mathrm{~F}$ & Forearm & Ulcer \& Pyoderma \\
\hline 3 & 21 & $\mathrm{~F}$ & Forearm & Ulcer \& Pyoderma \\
\hline 4 & 20 & $\mathrm{~F}$ & Thigh & Ulcer \& Pyoderma \\
\hline 5 & 17 & $\mathrm{~F}$ & Buttock & Ulcer \& Pyoderma \\
\hline 6 & 25 & $\mathrm{~F}$ & Arm & Ulcer \& Pyoderma \\
\hline 7 & 23 & $\mathrm{~F}$ & Wrist & Ulcer \& Pyoderma \\
\hline 8 & 24 & $\mathrm{~F}$ & Both Popliteal Fossae & Ulcer \& Pyoderma \\
\hline 9 & 20 & $\mathrm{~F}$ & Forearm & Ulcer \& Pyoderma \\
\hline 10 & 23 & $\mathrm{~F}$ & Forearm & Ulcer \& Pyoderma \\
\hline 11 & 19 & $\mathrm{~F}$ & Forearm & Ulcer \& Pyoderma \\
\hline
\end{tabular}

for any reason. There was no history of alcohol/drug abuse or serious anti-social behavior. The site of injection was usually on accessible areas and all seen on the limbs. One case study of patient number eleven is reported here. A thorough psychiatric semi-structured interview has been conducted with one of the patients as a detailed example:

A 19-year old Iraqi Muslim single girl, a student in the college of education, living in Baghdad with her parents and younger two brothers, was brought to the emergency Department of Baghdad Teaching Hospital Medical City in March 2010 after three days of outpatient treatment by a private local doctor, where she received cortisone ointment and analgesic tablets for suspected erosive contact dermatitis on her left arm without improvement. The lesion was expanding to involve the whole arm with generalized redness and swelling and in ability to move it freely with intensifying pain and tenderness for which she was referred for consultation. The Patient admitted using a $5 \mathrm{ml}$ disposable syringe filled with household kerosene injecting it into her left arm just below the cubital fossa. This was in response to her total failure in her first term examination four days before consultation. She was taught about this method by a friend in the college. Urgent surgical debridement of the all necrotic and a vascular tissues was done under anesthesia. Minor injury to the flexors of the forearm occurred, but did not affect full movement. She had neither previous medical or psychiatric problems nor family history of mental illness. She was described as a pleasant friendly girl by her mother with no record of impulsivity or antisocial behavior. The patient denied any emotional or family conflict. Both parents were college graduates and government employees living in comfortable accommodation with a reasonable financial status. On assessing her mental state, she was fully conscious and alert with the injured arm wrapped up to the wrist and an intravenous fluid containing anti-biotic running in the healthy arm, but looked pale and gloomy. Speech was coherent and logical, there were no thought or perceptual disorders, her affect were sad and congruent with her mood. She expressed full ignorance of the toxic nature of kerosene and denied any suicidal thoughts justifying her act as a self punishment for school failure. She denied feeling psychological relief by the injection and expressed regret and concerns about future disfigurement or paralysis. The patient was jointly followed up in the skin clinic and psychiatry outpatient clinic in the Medical City Teaching Hospital according to an appointment protocol.

In eight cases the injection was on the upper arms specifically on the forearms while three cases on the lower limbs specifically thigh, buttock, popliteal fossae.

Patients were seen after few days to few weeks following the injection. The course of the disease started as erythematous plaques that were hot and tender simulating a picture of panniculitis, after awhile there was rupture of the lesions leaving discharging deep ulcers. No smell of kerosene was detected in any lesion. These ulcers were managed by antiseptic clearance, topical and oral antibiotics were given, and the healing time took few too many weeks. In all cases there was disfiguring scar at the site of injection and one patient with the wrist injection left severe fibrosis and contracture of the wrist and hand.

The scars were managed by strong topical steroid ointment with oral antihistamine to improve the cosmetic appearance (Figure 1 and Figure 2). 


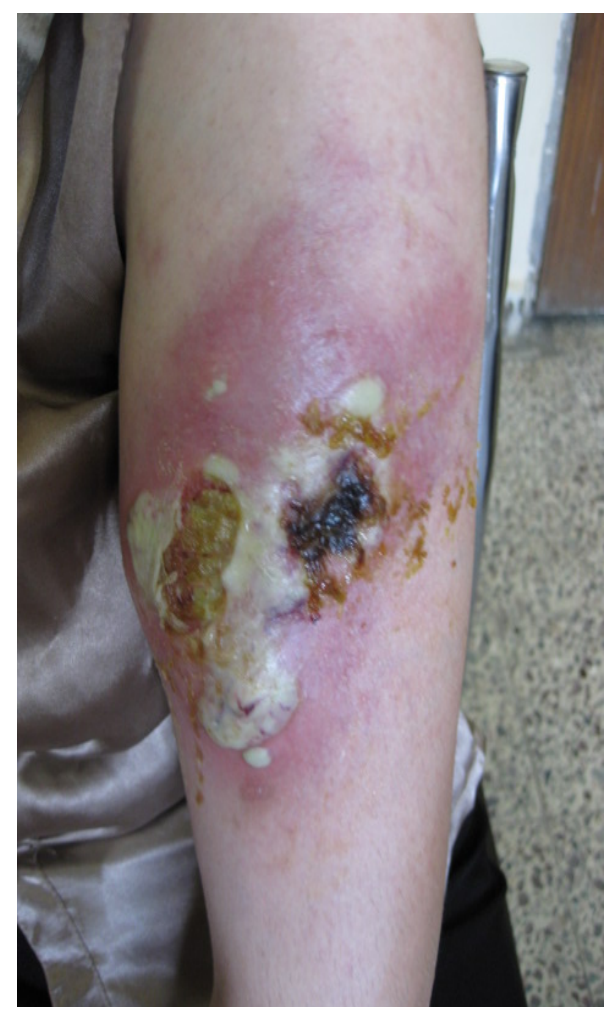

Figure 1. Showing female patient with kerosene intradermal injection presented with pyoderma of right upper arm.

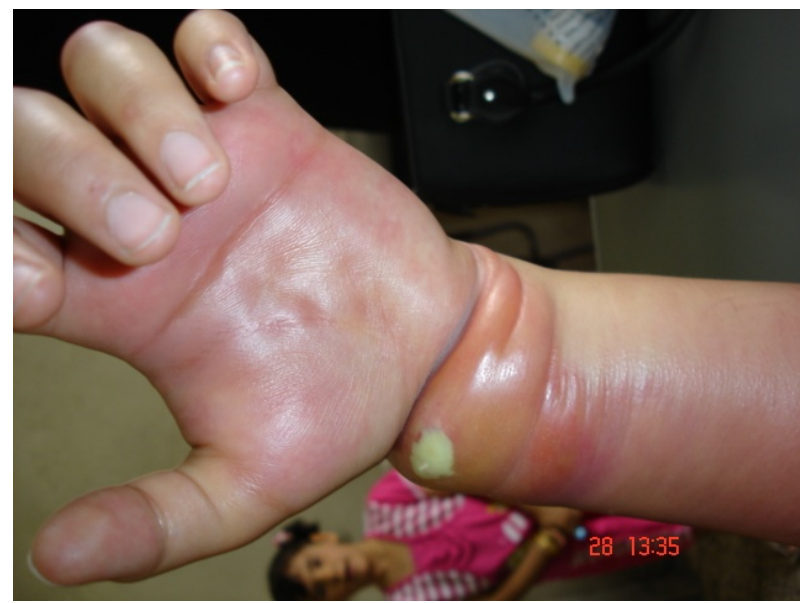

Figure 2. Showing panniculitis is and pyoderma in the left wrist in female patient.

\section{Discussion}

US Occupation of Iraq caused severe economic, social and psychological problems among population and one of these medical problems is doing kerosene injection. Kerosene is a mixture of hydrocarbons [11] [12], which can cause severe inflammation and necrosis of all layers of the skin even and can involve the fascia and the underlying muscles. But clinically as seen in the present work all features of panniculitis were observed. So we preferred the term panniculitis rather than fasciitis. As a kind of chronic ulcer it might also simulate the picture of pyoderma gangrenosum. In searching the medical literatures, we came across only four cases of so called fasciitis and panniculitis, which were all in Arab world [8]-[10]. In Iraq, there is an increasing report about this problem within the 
last ten years [13].

Initial diagnosis is very essential in order to achieve successful management of these cases, so any panniculitis like pictures on accessible area commonly the upper arms of young female, kerosene injection should be highly suspected. Immediate management including hospital admission and urgent surgical debridement should be carried out to evacuate the remaining kerosene in the tissue with full antibiotic cover, while the condition is seen as chronic discharging ulcer and management including cleaning with antiseptic, topical antibiotic and systemic antibiotics cover. In late cases scarring could be managed by topical steroid ointment and cosmetic surgery might be arranged.

Emotional tensions that can lead to skin diseases are those like dermatitis artefecta, trichotillomenia, delusion of parasitosis and others. These cases are not uncommon problems seen in daily clinical practice.

Self-inflicted dermatosis induced by kerosene is not well documented in Iraqi medical literatures, but during Iran-Iraq war 1980-1988, cases of intradermal kerosene injection are practiced by soldiers during the army attacks in order to have sick leave [14] [15]. It is well known that children may ingest kerosene instead of water, while adults may burn themselves by bathing with kerosene [7] [13]-[16].

In the last ten years cases of intradermal kerosene injection had been seen as a part of emotional problems but unfortunately all cases are misdiagnosed initially as most doctors are not aware of this problem.

So the aim of the present report is to present the clinical picture of these cases to encourage doctors to have right initial diagnosis.

In conclusion self-induced panniculitis by intradermal kerosene injection is a distinctive entity that should be managed early to have right treatment and to avoid future complications. Psychological evaluation should be carried out in all cases.

\section{Disclosure}

This study was an independent study and not funded by any drug companies.

\section{References}

[1] Rice, R.H. and Mauro, T.M. (2008) Toxic Responses of the Skin. In: Casarett, L.J., Ed., Casarett and Doull's Toxicology: The Basic Science of Poisons, 7th Edition, McGraw-Hill, New York, 143-518.

[2] Baynes, R.E., Brooks, J.D., Budsaba, K., Smith, C.E. and Riviere, J.E. (2001) Mixture Effects of JP-8 Additives on the Dermal Disposition of Jet Fuel Components. Toxicology and Applied Pharmacology, 175, 269-281. http://dx.doi.org/10.1006/taap.2001.9259

[3] Nixon, S.A. (1985) Kerosene Induced Abscesses. Archives of Internal Medicine, 145, 1743. http://dx.doi.org/10.1001/archinte.1985.00360090219045

[4] Rao, G.S., Kannan, K., Goel, S.K., Pandya, K.P. and Shanker, R. (1984) Subcutaneous Kerosene Toxicity in Albino Rats. Environmental Research, 35, 516-530.

[5] Terzi, C., Bacakoglu, A., Unek, T. and Ozkan, M.H. (2002) Chemical Necrotizing Fasciitis Due to Household Insecticide Injection: Is Immediate Surgical Debridement Necessary? Human Experimental Toxicology, 21, 687-690. http://dx.doi.org/10.1191/0960327102ht308cr

[6] Enchsen, H. and Lynge, P. (1979) Chemical Inflammation and Subcutaneous Necrosis after Injection of Benzene. Ugeskrift for Lager, 141, 1337.

[7] Al-Dabbas, M.H. (2006) Deliberate Self-Burning: The Psychosocial and Clinical Patterns among Patients Admitted to Burn Unit in King Hussein Medical Center/Jordan. The Arab Journal of Psychiatry, 17, 253-256.

[8] Awe, A.J., Soliman, M.A. and Gourdie, R.W. (2003) Necrotizing Fasciitis Induced by Self-Injection of Kerosene. Annals of Saudi Medicine, 23, 388-390.

[9] Nazar, M. (2012) Mohammad Amin, Nashmeel Rasool Hamah Ameen, Reem Abed, Mohammed Abbas. Self-Burning in Iraqi Kurdistan: Proportion and Risk Factors in a Burns Unit. International Psychiatry, 9, 72-74.

[10] Apex Oil Company, Inc. (2005) Material Safety Data Sheet, Kerosene: (Straight Run, Hydrodesulfurized, Clear or Dyed). http://www.apexoil.com/msds/kero.pdf

[11] Wikipedia (The Free Encyclopedia) (2012) History of Petroleum.

[12] Karam, G.E., Hajjar, R.V. and Salamoun, M.M. (2007) Suicidality in the Arab World Part I: Community Studies. The Arab Journal of Psychiatry, 18, 99-107.

[13] Hosseinian, A, Mahammad, A.T.J. and Alireza, R. (2009) Clinical Finding and Outcome in Suicidal Attempt Due to 
Intravenous Injection of Kerosene. Pakistan Journal of Biological Sciences, 12, 439-442. http://dx.doi.org/10.3923/pjbs.2009.439.442

[14] Kafaween, H., Rbehat, H. and Hawil, K.N. (2010) Necrotizing Fascitis Induced by Self-Injection of Kerosene, Case Report. The Middle East Journal of Family Medicine, 8, 35-39.

[15] Khammash, M.R., Hussein, A.D. and Musmer, M. (1997) Management of Kerosene Injection in the Upper Limb. Saudi Medical Journal, 18, 188-190.

[16] Younis, M.S. (2012) Self-Mutilation by Subcutaneous Injection of Kerosen: Report from Iraq. 12th Pan Arab Psychiatric Conference, 29-30 November-1 December 2012.

[17] Hassan, H.S. (1999) Self Mutilation. The Arab Journal of Psychiatry, 10. http://www.arabjpsychiat.com/index.php?option=com content\&view=article\&id=28:1999vol102november\&catid=1:v olumes-a-articles\&Itemid=2 
Scientific Research Publishing (SCIRP) is one of the largest Open Access journal publishers. It is currently publishing more than 200 open access, online, peer-reviewed journals covering a wide range of academic disciplines. SCIRP serves the worldwide academic communities and contributes to the progress and application of science with its publication.

Other selected journals from SCIRP are listed as below. Submit your manuscript to us via either submit@scirp.org or Online Submission Portal.
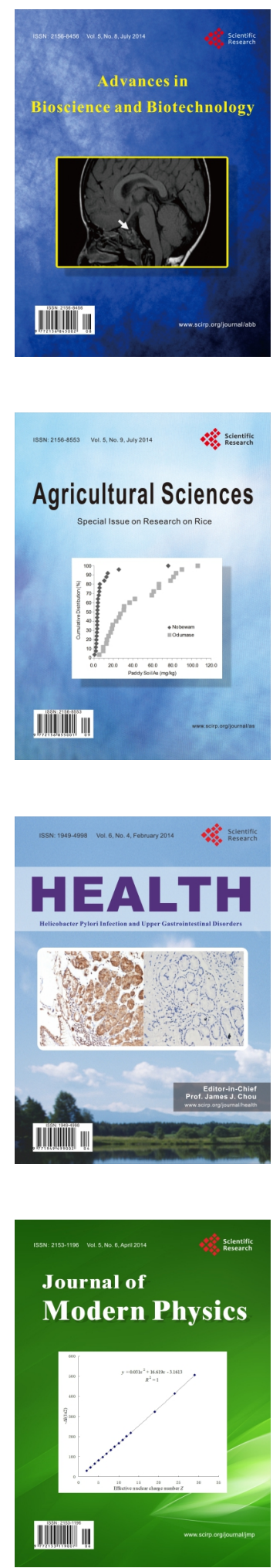
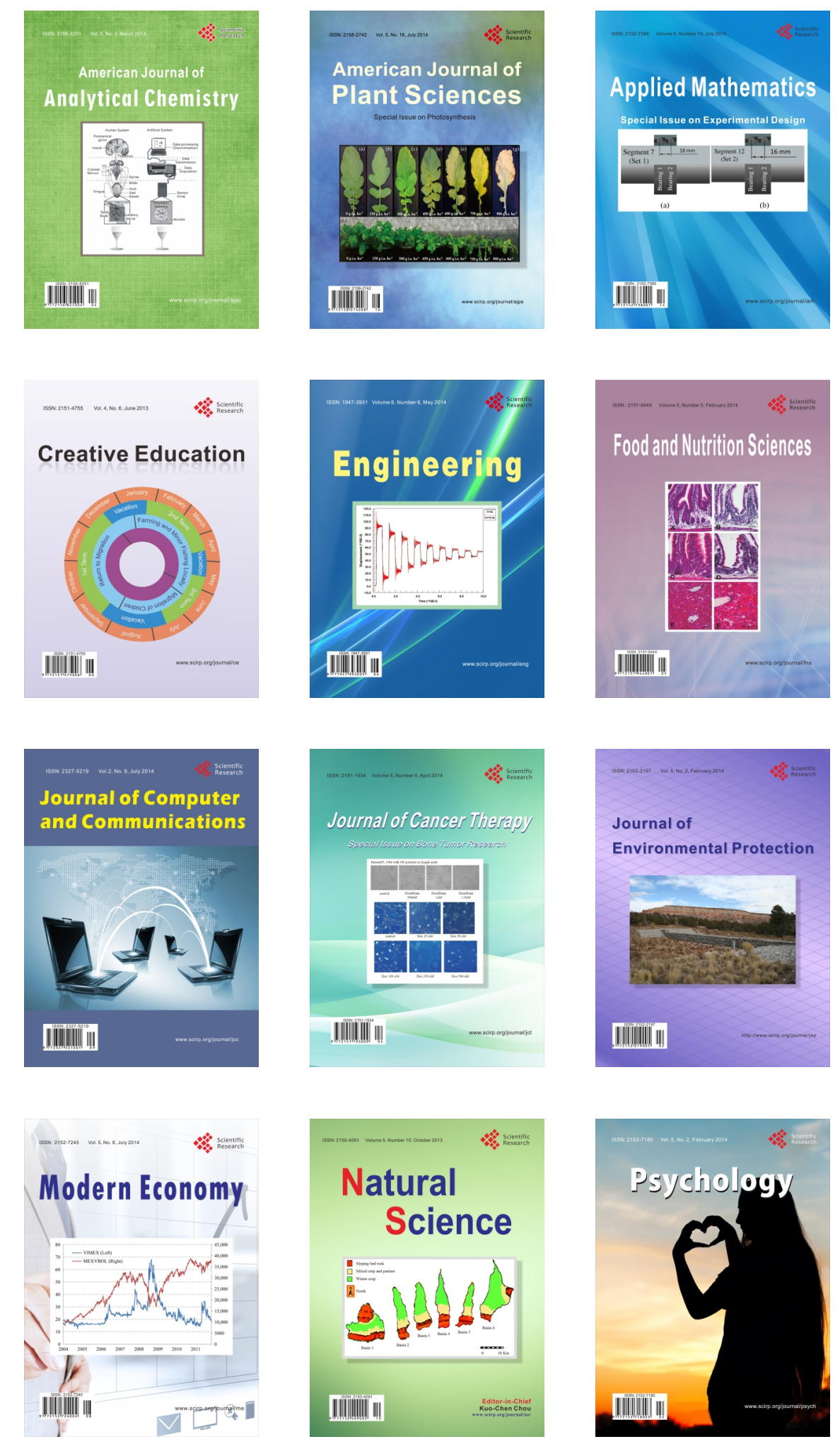